\section{Características de gestão, funcionamento e cardápios do Programa Nacional de Alimentação Escolar em escolas Kaingáng do Rio Grande do Sul, Brasil}

\author{
Management, operations, and menus in Kaingáng \\ indigenous schools participating in the National \\ School Nutrition Program in Rio Grande do Sul \\ State, Brazil
}

\author{
Características de la gestión, la operatividad y los \\ menús del Programa Nacional de Alimentación \\ Escolar en escuelas Kaingáng de Río Grande do \\ Sul, Brasil
}

\begin{abstract}
Few studies have focused on the National School Nutrition Program (PNAE) in indigenous schools in Brazil. The current study describes the program's operations, management, and menus in 35 Kaingáng indigenous schools in Rio Grande do Sul State, Brazil. A cross-sectional study design was used to obtain information on the program through questionnaires submitted to the Regional Educational Offices (CRE) and to the schools. The menus suggested to the schools by the regional offices were obtained. There were no Centers for Indigenous Education in the regional offices. All the assistant principals were indigenous, 26 schools (74.6\%) practiced local management of the meal program, and 34 (97.1\%) reported purchasing food from local markets. Most cooks (63.9\%) had temporary work contracts with the schools and $65.7 \%$ were indigenous. Low offerings of vegetables, milk and dairy products were observed in around 60\% of the menus, and legumes and fruits low in around $80 \%$. It points out the need for more studies about the indigenous PNAE and intends to support public policies in health, food and nutrition for the national indigenous school.
\end{abstract}

Health of Indigenous Peoples; South American Indians; School Feeding
Teresa Gontijo de Castro 1

Elaine de Lima Cordeiro Matos 1

Maurício Soares Leite 2

Wolney Lisboa Conde 3

Ilaine Schuch 4

Juracilda Veiga 5

Priccila Zuchinali 4

Laura Augusta Barufaldi 6

Carmem Lúcia Centeno Dutra 7

\title{
Resumo
}

Há poucos estudos sobre o Programa Nacional de Alimentação Escolar (PNAE) em escolas indígenas no país. O objetivo do presente artigo é descrever características de funcionamento, gestão e cardápios do PNAE de todas as 35 escolas Kaingáng do Rio Grande do Sul, Brasil. Em estudo transversal, as informações do PNAE foram recolhidas por meio de questionários aplicados a cada Coordenadoria Regional de Educação (CRE) e às escolas. Foram obtidos os cardápios sugeridos pelas CREs às escolas. Não existia o Núcleo de Educação Indígena nas CREs. Todos os vice-diretores eram indigenas, 26 escolas $(74,6 \%)$ tinham gestão escolarizada e 34 escolas $(97,1 \%)$ compravam alimentos de mercados próximos. A maioria das merendeiras (62,9\%) tinha contrato de trabalho temporário e 65,7\% eram indígenas. Observou-se baixa oferta de verduras/legumes e de leite e derivados em cerca de $60 \%$ dos cardápios, o mesmo ocorrendo com leguminosas e frutas em cerca de $80 \%$ destes. Apontase a necessidade de mais estudos sobre o PNAE indígena e pretende-se subsidiar políticas públicas de saúde, alimentação e nutrição para o espaço escolar indígena nacional.

Saúde de Populações Indígenas; Índios Sul-Americanos; Alimentação Escolar 


\section{Introdução}

O Programa Nacional de Alimentação Escolar (PNAE) caracteriza-se como política pública na área de segurança alimentar e nutricional, que teve seu início no país na década de 1950. É considerado um dos mais abrangentes e duradouros na área de alimentação escolar do mundo ${ }^{1}$. Tem por objetivo atender às necessidades nutricionais dos alunos durante sua permanência em salas de aula de creches, pré-escolas, escolas do Ensino Fundamental das redes Federal, Estadual, do Distrito Federal e Municipal, inclusive as indígenas e as localizadas em áreas remanescentes de quilombos. Pretende, assim, contribuir para o crescimento e desenvolvimento dos alunos, para a aprendizagem e o rendimento escolar, bem como para a formação de hábitos alimentares saudáveis. O programa, de caráter suplementar, realiza a transferência de recursos financeiros, com base no censo escolar anual, do nível federal (Fundo Nacional de Desenvolvimento da Educação - FNDE) diretamente às entidades executoras: estados, municípios e escolas. Sobre as formas de gestão do PNAE, destacam-se principalmente a municipalizada (na qual as entidades executoras estaduais, por meio das secretarias municipais de educação, delegam aos municípios a função) e a escolarizada (na qual as entidades executoras estaduais e municipais repassam o recurso diretamente às escolas). Cumpre ressaltar que fazem parte também do PNAE os Conselhos de Alimentação Escolar (CAE), colegiados deliberativos que, instituídos no âmbito dos estados, Distrito Federal e municípios, cumprem a função de fiscalização e assessoramento do programa 2 .

De acordo com dados estatísticos oficiais, no período de 1995-2010, observou-se importante ampliação do PNAE, cuja cobertura passou de 33,2 milhões para 45,6 milhões de alunos, tendo sua alocação financeira subido de 590,1 milhões para três bilhões de reais 1 . Dentre outros aspectos incorporados ao programa a partir de 2003, destacam-se a extensão de sua cobertura a escolas de populações diferenciadas, como indígenas e quilombolas, com um valor per capita por aluno superior àquele destinado a alunos da sociedade envolvente 3 ; a obrigatoriedade de que as escolas indígenas e quilombolas forneçam, no mínimo, 30\% das necessidades nutricionais diárias dos alunos por refeição e, quando em período integral, no mínimo $70 \% 3$; a promulgação da Lei Federal no $11.947^{4}$ e da Resolução/CD/FNDE no 38, de 16 de julho de 2009 , as quais estipulam que, no mínimo, $30 \%$ do total dos recursos repassados do FNDE sejam destinados à compra de alimentos, preferencialmente orgânicos, pro- duzidos pela agricultura familiar local, regional ou nacional 5 . Em relação a este último aspecto, o programa intenciona impactar na vocação agrícola dos municípios, fomentando o desenvolvimento da economia local, além do incentivo e respeito aos hábitos e alimentos regionais. Outro aspecto de destaque refere-se à nova proposta de constituição e atribuição dos CAE, que, além de buscar a articulação de representantes de diferentes segmentos (poder executivo, profissionais da educação e discentes, representação de pais de alunos e da sociedade civil), deverá acompanhar a elaboração dos cardápios ofertados, tendo em sua constituição representante das comunidades indígenas e quilombolas, de forma a respeitar os hábitos alimentares de grupos populacionais específicos 3 .

No entanto, apesar das reformatações do programa nos últimos anos e de sua abrangência e relevância no cenário nacional e internacional, ainda são escassas as publicações científicas sobre a trajetória histórica, a abrangência, a eficiência e a eficácia do PNAE 1. Há poucos estudos sobre o programa no contexto não indígena $5,6,7,8,9,10,11,12$. No contexto indígena, menos ainda, os quais, basicamente, resumem-se a algumas dissertações de mestrado e a poucos artigos científicos. Pessôa 13 buscou descrever, em escolas Teréna, a origem e tipo de alimentos utilizados, a composição nutricional e a aceitabilidade das preparações, o funcionamento dos CAE e a investigação da existência de experiências de educação alimentar e nutricional. Os demais estudos, de cunho essencialmente etnográfico, objetivaram desenvolver e aplicar instrumentos metodológicos adequados para melhor compreensão do funcionamento do PNAE em contexto dos Mbyá Guarani 14; avaliar como se concretiza o respeito à diversidade sociocultural no programa em escola Xavánte 15; sistematizar informações relacionadas à segurança alimentar e nutricional, avaliando sua aplicabilidade, no PNAE em escolas da Terra Indígena (TI) Raposa Serra do Sol, em Roraima, Brasil 16.

A investigação da situação alimentar e nutricional dos povos indígenas tem se apresentado como um dos temas prioritários de saúde pública no país 17. Dados do último censo demográfico registram uma população indígena de mais 900 mil indivíduos, pertencentes a 305 etnias e falantes de 192 línguas, distribuídos por todos os estados da Federação. A diversidade que esses números traduzem é ainda maior quando consideradas as diferentes trajetórias históricas e de contato com o segmento não indígena da sociedade brasileira ${ }^{18}$. No que se refere às condições de saúde, alimentação e nutrição, os dados disponíveis apontam sistematicamente 
para condições amplamente desfavoráveis em face daquelas observadas entre não indígenas das mesmas regiões. Situações em que prevalecem condições sanitárias precárias, perfis epidemiológicos com predomínio de doenças infecciosas e parasitárias, nos quais a anemia e os déficits estaturais e ponderais infantis alcançam prevalências usualmente elevadas, mas que registram, também, com frequência crescente, obesidade e doenças crônicas não transmissíveis 19,20,21. Trata-se de uma enorme diversidade sociocultural e epidemiológica, caracterizando um segmento populacional a ser contemplado em suas especificidades - segundo a proposta do PNAE e, em última instância, da própria Política Nacional de Alimentação e Nutrição, em um programa de âmbito nacional. Diante desses dados e considerando-se a importância do PNAE no âmbito das ações estatais no campo da alimentação e nutrição no Brasil, como também seu grande potencial de impacto nas condições nutricionais de escolares, fica evidente a necessidade de estudos que descrevam em detalhe o funcionamento do programa nessas realidades.

Pelo exposto, este estudo objetiva descrever características de funcionamento, gestão e cardápios do PNAE nas escolas indígenas Kaingáng do Estado do Rio Grande do Sul.

\section{Métodos}

O estudo, de natureza transversal, foi realizado nas escolas indígenas Kaingáng do Estado do Rio Grande do Sul, Brasil. Os Kaingáng representam um dos cinco povos mais populosos, estando presentes nos estados de São Paulo, Paraná, Santa Catarina e Rio Grande do Sul. Totalizam 37.470 indivíduos, 31.814 dos quais viviam em TI, enquanto 2.656 ocupavam áreas ou municípios fora dos espaços de delimitação da TI 18. Atualmente, os Kaingáng têm a agricultura como elemento básico de sua economia, sendo esta direcionada tanto para consumo próprio, como para venda. Contudo, em virtude da restrição territorial e do esgotamento dos recursos naturais, o acesso aos alimentos acontece também por meio de aquisição comercial, feita em grande parte nos mercados das cidades mais próximas, e, eventualmente, pelo recebimento de cestas de alimentos 22,23 .

Este estudo foi realizado em todas as 35 escolas indígenas localizadas nas 12 Terras Indígenas Kaingáng do Estado do Rio Grande do Sul que estavam com situação fundiária reconhecida perante a Fundação Nacional do Índio (FUNAI) à época do trabalho de campo, transcorrido de julho a dezembro de 2008. Naquele momento, havia 4.662 indígenas matriculados nas instituições de ensino. Na presente pesquisa, a descrição do PNAE nas escolas Kaingáng foi feita essencialmente com base em duas perspectivas: a das diretrizes do programa, com especial atenção para as especificidades do seu funcionamento nas escolas indígenas 2,3,4,24, e a das recomendações do Guia Alimentar para a População Brasileira 25, aqui entendido como instrumento fundamental da Política Nacional de Alimentação e Nutrição para a promoção da alimentação saudável no país.

Para isso, informações sobre funcionamento e gestão do PNAE foram obtidas mediante a aplicação de questionários estruturados nas escolas e em cada Coordenadoria Regional de Educação (CRE-RS) que cobriam as instituições em estudo. No Rio Grande do Sul, as CREs, vinculadas à Secretaria Estadual de Educação, são responsáveis pelas políticas relacionadas às suas regiões, tendo como atribuições coordenar, orientar e supervisionar escolas, oferecendo suporte administrativo e pedagógico para a viabilização das políticas da secretaria. O questionário aplicado nas escolas foi destinado aos diretores e vicediretores; entretanto, de forma não uniforme, em algumas entrevistas, participavam também professores Kaingáng, agentes de assuntos educacionais, merendeiras e representantes do "Círculo de Pais e Mestres”. O instrumento foi aplicado por quatro nutricionistas previamente capacitadas. Nas CREs, as entrevistas, conduzidas por uma única nutricionista, foram realizadas com os responsáveis pela educação indígena e/ou responsáveis pela alimentação escolar. Em adição, nesses encontros, foram obtidos os cardápios sugeridos pelas coordenadorias às escolas em estudo, relativos ao último mês.

O questionário aplicado às escolas continha as seguintes informações: níveis de ensino, turnos de funcionamento, presença de indígenas não matriculados e participação destes na alimentação escolar, falta de merenda no ano anterior à entrevista, existência de direção e vice-direção indígenas, tipo de gestão do PNAE (escolarizada ou municipalizada), processos de licitação e compra de gêneros alimentícios, existência de doação de alimentos. As informações relativas à alimentação eram: se a escola recebia sugestão de cardápio, se o executava e se havia conhecimento dos CAE; abordava também questões relativas à existência de horta e do uso dos produtos desta na alimentação escolar, local de armazenagem de gêneros alimentícios e existência de refeitório, caixa d'água e sistema regular de coleta de lixo. Além disso, continha questões sobre se as merendeiras eram indígenas, sua escolaridade, capacitação e forma de seleção e contrato. 
O questionário aplicado às CREs trazia questões relativas à existência do Núcleo de Educação Indígena e de assessorias antropológicas àquelas, à diferenciação entre os cardápios sugeridos pelas coordenadorias para as escolas indígenas e as não indígenas, à existência dos CAE nos municípios onde se localizavam as escolas e à existência de representação indígena nestes conselhos. Os cardápios obtidos nas CREs eram elaborados por nutricionistas, dia a dia, para cada escola (que considerava 20 dias letivos ao mês). Em análise nutricional realizada de forma qualitativa, avaliou-se a presença dos grupos de alimentos segundo definição do Guia Alimentar para a População Brasileira 25: cereais e tubérculos; verduras e legumes; frutas; leguminosas; carnes, peixes e ovos; leites e derivados; óleos e gorduras; açúcares e doces. Foram também criados, para fins de análise, dois grupos adicionais, o dos embutidos (para englobar mortadela, salsicha e presunto) e o dos enlatados (para englobar milho, ervilha, sardinha, atum e molho de tomate). Criou-se, ainda, uma variável indicadora da qualidade nutricional das preparações sugeridas, sendo definidos como de qualidade nutricional cardápios que incluíam três ou mais diferentes grupos alimentares em suas preparações diárias (excetuando-se a presença do grupo dos açúcares, gorduras, embutidos e enlatados).

Este estudo foi aprovado em todas as instâncias requeridas para pesquisas com povos indígenas no Brasil 26: Comitê de Ética em Pesquisa da Universidade Federal do Rio Grande do Sul (protocolo no 2007726), Comissão Nacional de Ética em Pesquisa (protocolo no 14.449), Conselho Nacional de Desenvolvimento Científico e Tecnológico (CNPq) e FUNAI (processo no 1141/08 CGEP/08). Antes de iniciar a investigação, o representante local da FUNAI, em conjunto com o pesquisador coordenador, solicitou às lideranças das comunidades o consentimento para a realização da pesquisa, tendo sido obtida a aprovação oral e escrita de todos. Ao final do estudo, relatórios com os resultados individuais foram entregues às escolas.

A dupla digitação dos dados foi realizada no programa Epi Info 6.04 (Centers for Disease Control and Prevention, Atlanta, Estados Unidos) e estes foram analisados no programa SPSS 13.0 (SPSS Inc., Chicago, Estados Unidos). Foram calculadas as frequências das variáveis categóricas.

\section{Resultados}

Todas as escolas estudadas ofereciam o ensino fundamental, aproximadamente um quarto ofertava o curso de Educação de Jovens e Adultos, e a educação infantil só existia em pequeno percentual dessas instituições $(n=3 ; 8,6 \%)$. A grande maioria funcionava em dois turnos: matutino e vespertino ( $\mathrm{n}=32 ; 91,4 \%)$. Dentre as escolas, 15 $(42,8 \%)$ relataram a existência de indígenas não matriculados, mas que as frequentavam. Dezoito escolas $(51,4 \%)$ mencionaram que indígenas não matriculados partilhavam da alimentação ofertada. A falta de merenda em algum momento do ano que antecedeu a data da entrevista foi mencionada por uma das escolas. A maioria $(57,1 \%)$ contava com horta e relatou utilizar os produtos desta no preparo da alimentação escolar. Em 23 escolas $(65,7 \%)$ os gêneros alimentícios eram armazenados na cozinha ou refeitório, todavia, as escolas restantes relataram a armazenagem dos alimentos em locais como despensa, diretoria e secretaria. Dentre as escolas, 24 (68,6\%) mencionaram não ter refeitório, 11,4\% referiram não ter caixa d'água e $45,7 \%$ delas não tinham sistema regular de coleta de lixo (dados não apresentados em tabela).

Outras informações sobre a gestão e o funcionamento do PNAE nas escolas são apresentadas na Tabela 1. Todos os diretores eram não indígenas, e uma escola estava sem diretor na ocasião. Todos os vice-diretores eram indígenas. A grande maioria das escolas tinha a gestão escolarizada do PNAE, de modo que os processos de licitação e compra de produtos para a alimentação escolar eram realizados pelos diretores, enquanto as demais contavam com a gestão municipalizada do programa, conduzida pelas secretarias municipais de educação dos municípios onde se localizavam as TI. Grande parte das escolas relataram obter os gêneros alimentícios de mercados próximos à TI, e 14,3\% referiram também obter alguns produtos da agricultura indígena (principalmente o feijão e a mandioca). A maioria das escolas relatou receber sugestão de cardápio das coordenadorias regionais de educação, mas somente $11,4 \%$ afirmaram que os executavam integralmente. Chamou a atenção o fato de quase $70 \%$ dos entrevistados nas escolas não saberem do que se tratava os CAE.

Características relacionadas às merendeiras são apresentadas na Tabela 2. Estas, em sua maioria, eram indígenas. Em relação à escolaridade, $32,1 \%$ tinham até quatro anos de ensino formal, enquanto $64,1 \%$ contavam com mais de quatro anos de ensino formal. Em dez escolas (28,5\%), o preparo das refeições era auxiliado ou realizado por outros profissionais. À época da pesquisa, duas escolas não contavam com a presença desse profissional. A maioria das seleções das merendeiras era realizada mediante o Programa de Apoio ao Desenvolvimento do Ensino Fundamental - PRADEN; seguida da contrata- 
Tabela 1

Características de funcionamento e gestão do Programa Nacional de Alimentação Escolar nas escolas indígenas Kaingáng, Rio Grande do Sul, Brasil, 2008 ( $N=35$ escolas).

\begin{tabular}{|c|c|c|}
\hline Variável & $\mathrm{n}$ & $\%$ \\
\hline \multicolumn{3}{|l|}{ Quem é o diretor? } \\
\hline Não indígena & 34 & 97,1 \\
\hline Não há diretor na escola & 1 & 2,9 \\
\hline \multicolumn{3}{|l|}{ Quem é o vice-diretor? } \\
\hline Indígena & 35 & 100,0 \\
\hline \multicolumn{3}{|l|}{ Tipo de gestão } \\
\hline Municipalizada & 9 & 25,7 \\
\hline Escolarizada & 26 & 74,3 \\
\hline \multicolumn{3}{|l|}{ Quem faz a licitação da alimentação escolar? } \\
\hline Diretor & 25 & 71,4 \\
\hline Prefeitura & 9 & 25,7 \\
\hline Diretor e professor indígena & 1 & 2,9 \\
\hline \multicolumn{3}{|l|}{ Quem faz as compras da alimentação escolar? } \\
\hline Diretor & 25 & 71,4 \\
\hline Prefeitura & 9 & 25,7 \\
\hline Diretor e professor indígena & 1 & 2,9 \\
\hline \multicolumn{3}{|l|}{ Onde são comprados os gêneros alimentícios? * } \\
\hline No mercado mais próximo & 34 & 97,1 \\
\hline No município polo & 1 & 2,9 \\
\hline De colonos fora da Terra Indígena & 2 & 5,7 \\
\hline Agricultura indígena & 5 & 14,3 \\
\hline \multicolumn{3}{|l|}{ A escola recebe doação de alimentos? } \\
\hline Sim & 30 & 85,7 \\
\hline Não & 5 & 14,3 \\
\hline \multicolumn{3}{|l|}{ A escola recebe sugestão de cardápio? } \\
\hline Sim & 31 & 88,6 \\
\hline Não & 4 & 11,4 \\
\hline \multicolumn{3}{|l|}{ Que setor sugere o cardápio? } \\
\hline Coordenadoria Regional de Educação & 25 & 71,4 \\
\hline Outra escola & 1 & 2,9 \\
\hline Prefeitura do município onde se localiza a Terra Indígena & 5 & 14,3 \\
\hline Não se aplica & 4 & 11,4 \\
\hline \multicolumn{3}{|l|}{ O cardápio sugerido é executado? } \\
\hline Não & 9 & 25,8 \\
\hline Sim, totalmente & 4 & 11,4 \\
\hline Sim, parcialmente & 18 & 51,4 \\
\hline Não se aplica & 4 & 11,4 \\
\hline \multicolumn{3}{|l|}{ A escola conhece o Conselho de Alimentação Escolar? } \\
\hline Sim & 12 & 34,3 \\
\hline Não & 23 & 65,7 \\
\hline
\end{tabular}

* Podia ser dada mais de uma resposta para a pergunta. 
Tabela 2

Características relacionadas às merendeiras das escolas indígenas Kaingáng, Rio Grande do Sul, Brasil, 2008 ( N = 35 escolas).

\begin{tabular}{|c|c|c|}
\hline Variável & n & $\%$ \\
\hline \multicolumn{3}{|l|}{ Quem são as merendeiras? } \\
\hline Indígenas & 23 & 65,7 \\
\hline Não indígenas & 10 & 28,6 \\
\hline Não há merendeiras & 2 & 5,7 \\
\hline \multicolumn{3}{|l|}{ Quem prepara as refeições? } \\
\hline Merendeira & 25 & 71,4 \\
\hline Auxiliar de serviços gerais & 1 & 2,9 \\
\hline Professor & 2 & 5,7 \\
\hline Merendeira e auxiliar de serviços gerais & 4 & 11,4 \\
\hline Merendeira, auxiliar de serviços gerais, diretores e professores & 3 & 8,6 \\
\hline \multicolumn{3}{|l|}{ Merendeira recebeu capacitação para a função de preparo das refeições? } \\
\hline Sim & 18 & 51,4 \\
\hline Não & 17 & 48,6 \\
\hline \multicolumn{3}{|l|}{ Quantas merendeiras há na escola? } \\
\hline Nenhuma & 2 & 5,6 \\
\hline Uma & 17 & 48,6 \\
\hline Duas & 12 & 34,3 \\
\hline Três ou mais & 4 & 11,5 \\
\hline \multicolumn{3}{|l|}{ Escolaridade das merendeiras (anos de estudo) } \\
\hline Analfabeta & 1 & 1,9 \\
\hline $1-4$ & 15 & 28,3 \\
\hline $5-7$ & 16 & 30,1 \\
\hline Ensino Fundamental e Ensino Médio completo & 14 & 26,4 \\
\hline Superior incompleto ou completo & 4 & 7,6 \\
\hline Não soube informar & 3 & 5,7 \\
\hline \multicolumn{3}{|l|}{ Como foram selecionadas? } \\
\hline Concurso público & 8 & 22,9 \\
\hline Indicação & 1 & 2,9 \\
\hline Concurso+Indicação & 1 & 2,9 \\
\hline Pelo Programa de Apoio ao Desenvolvimento do Ensino Fundamental - PRADEN & 20 & 57,0 \\
\hline Outros & 3 & 8,6 \\
\hline Não se aplica & 2 & 5,7 \\
\hline \multicolumn{3}{|l|}{ Qual a forma de contrato estabelecido com as merendeiras? } \\
\hline Estatutário ou celetista & 9 & 25,7 \\
\hline Contrato temporário & 22 & 62,9 \\
\hline Outros & 2 & 5,7 \\
\hline Não há merendeiras & 2 & 5,7 \\
\hline
\end{tabular}

ção via concurso público. No entanto, a maior parte dos contratos era realizada em regime temporário, com duração, a cada ano, de abril a dezembro. Quase metade das merendeiras não havia recebido capacitação prévia sobre o preparo das refeições.

No Rio Grande do Sul, eram cinco as CREs que cobriam as escolas indígenas sob estudo, localizadas nos municípios de Erechim (que cobria as escolas das TIs de Cacique Doble, Ligei- ro, Ventarra e Votouro), Passo Fundo (escolas de Carreteiro, Monte Caseros e parte das escolas da TI de Nonoai), Três Passos (escolas de Guarita e Inhacorá), Palmeira das Missões (escolas das TIs de Iraí, Rio da Várzea e Nonoai) e Carazinho (escolas da TI de Serrinha).

Informações sobre gestão e funcionamento do Programa, obtidas a partir destas instâncias, apontaram que em nenhuma delas havia o Núcleo de Educação Indígena, e apenas uma CRE re- 
latou a ocorrência de assessorias antropológicas, ofertadas anualmente pela Secretaria Estadual de Educação do Rio Grande do Sul. Quatro CREs afirmaram a existência de diferenciação das preparações entre os cardápios sugeridos para as escolas indígenas e para as não indígenas. Dos 19 municípios que cobriam as TIs observadas, em sete havia os CAE, porém somente um deles contava com membro indígena em sua composição (dados não apresentados em tabela).

Foi possível obter os cardápios sugeridos pelas CREs em 27 escolas (77,1\% das estudadas). Destas, $70,4 \%$ dos cardápios eram relativos ao mês anterior à entrevista; $14,8 \%$, aos dois meses anteriores; e $14,8 \%$, aos três meses anteriores. Verificou-se que somente para uma escola foram sugeridas preparações que contivessem a variável indicadora da qualidade das refeições para todos os dias letivos, ao passo que, para seis escolas $(22,2 \%)$, sugeriram-se essas preparações em 50\% dos dias letivos do mês. Para mais de 70\% das escolas, refeições com três grupos alimentares ou mais foram sugeridas para $25 \%$ ou menos dos dias letivos do mês (dados não apresentados em tabela). A Tabela 3 apresenta a distribuição das escolas de acordo com o percentual de dias em que os diferentes grupos alimentares eram ofertados ao mês. Destacou-se a baixa sugestão de oferta (feita para menos de $25 \%$ dos dias letivos) de verduras e legumes, de leite e derivados (quase $60 \%$ dos cardápios), assim como de leguminosas e frutas (cerca de $80 \%$ dos cardápios).

\section{Discussão}

O presente estudo apresentou descrição abrangente sobre a gestão e funcionamento do PNAE, em especial no que diz respeito aos cardápios oferecidos nas escolas indígenas Kaingáng do Rio Grande do Sul. Identificaram-se, como questões a serem priorizadas pelos gestores do programa em nível local e central, problemas relativos ao espaço físico nas escolas e à qualidade nutricional dos cardápios sugeridos a estas. Mas o maior desafio que se apresenta para o programa e seus gestores, em face da reconhecida vulnerabilidade social e nutricional dos povos indígenas no Brasil, é o de contemplar a especificidade destes, garantindo a participação do indígena nos CAE, a elaboração de cardápios adequados às escolhas alimentares Kaingáng contemporâneas, aspecto em que os CAE podem exercer um efetivo papel de controle social, e a constituição de Núcleos de Educação Indígena nas CREs.

Como principal resultado deste estudo, destaca-se a presença significativa dos indígenas em cargos vinculados ao PNAE: todos os vice-diretores e mais da metade das merendeiras eram indígenas. Por outro lado, é preocupante o fato de que quase $70 \%$ dos entrevistados nas escolas desconheciam do que se tratava os CAE, além da baixa representatividade indígena nestes conselhos. Quanto ao espaço físico escolar, ressaltouse a ausência de refeitórios na maioria das escolas e de local adequado para armazenagem de gêneros alimentícios em um percentual relevante, além da inexistência de um sistema regular de

Tabela 3

Presença dos diferentes grupos de alimentos nos cardápios sugeridos às escolas estudadas no mês analisado, Rio Grande do Sul, Brasil, 2008 ( $N=27$ escolas).

\begin{tabular}{|c|c|c|c|c|c|c|c|c|c|c|}
\hline \multirow[t]{3}{*}{ Grupos de alimentos } & \multicolumn{10}{|c|}{ No mês, ofertava } \\
\hline & \multicolumn{2}{|c|}{$100 \%$ dias } & \multicolumn{2}{|c|}{$99 \%-75 \%$ dias } & \multicolumn{2}{|c|}{$74 \%-50 \%$ dias } & \multicolumn{2}{|c|}{$49 \%-25 \%$ dias } & \multicolumn{2}{|c|}{$\begin{array}{c}\text { Menos 25\% } \\
\text { dias }\end{array}$} \\
\hline & $\mathrm{n}$ & $\%$ & $\mathrm{n}$ & $\%$ & $\mathrm{n}$ & $\%$ & $\mathrm{n}$ & $\%$ & $\mathrm{n}$ & $\%$ \\
\hline Cereais e tubérculos & 15 & 55,6 & 11 & 40,7 & 1 & 3,7 & 0 & 0,0 & 0 & 0,0 \\
\hline Verduras e legumes & 0 & 0,0 & 0 & 0,0 & 0 & 0,0 & 12 & 44,4 & 15 & 55,6 \\
\hline Leite e derivados & 0 & 0,0 & 1 & 3,7 & 0 & 0,0 & 10 & 37,0 & 16 & 59,3 \\
\hline Leguminosas & 0 & 0,0 & 0 & 0,0 & 0 & 0,0 & 5 & 18,5 & 22 & 81,5 \\
\hline Carnes e ovos & 0 & 0,0 & 2 & 7,4 & 18 & 66,7 & 7 & 25,9 & 0 & 0,0 \\
\hline Frutas & 0 & 0,0 & 0 & 0,0 & 0 & 0,0 & 6 & 22,2 & 21 & 77,8 \\
\hline Óleos e gorduras & 0 & 0,0 & 0 & 0,0 & 1 & 3,7 & 2 & 7,4 & 24 & 88,9 \\
\hline Doces e açúcares & 0 & 0,0 & 1 & 3,7 & 3 & 11,2 & 11 & 40,7 & 12 & 44,4 \\
\hline Embutidos & 0 & 0,0 & 0 & 0,0 & 0 & 0,0 & 5 & 18,5 & 22 & 81,5 \\
\hline Enlatados & 0 & 0,0 & 0 & 0,0 & 1 & 3,8 & 13 & 48,1 & 13 & 48,1 \\
\hline
\end{tabular}


coleta de lixo em quase metade das instituições. A inexistência do Núcleo de Educação Indígena nas CREs e a escassez da oferta de assessorias antropológicas a estas merecem destaques, assim como a inadequação nutricional dos cardápios sugeridos pelas coordenadorias às escolas, ilustrados, principalmente, pela baixa oferta de verduras e legumes, leguminosas, frutas e leite e derivados.

Acerca da estrutura das instalações físicas das escolas, cumpre ressaltar que, segundo Santos et al. 7, em abordagem sobre a estrutura técnico-organizacional necessária para operacionalização do programa, os recursos repassados da esfera federal para as esferas descentralizadas destinam-se exclusivamente à compra de gêneros alimentícios. Portanto, para a operacionalização adequada do PNAE, cabe ao município onde se situam as terras indígenas arcar com a responsabilidade de fornecer infraestrutura mínima para a preparação das refeições. A verificação de que a maioria das escolas tinha horta e relatou utilizar os produtos desta na alimentação ofertada, juntamente ao fato de que cerca de $15 \%$ das instituições adquiriam alguns gêneros da alimentação escolar oriundos da agricultura indígena, é de destaque. Ressalta-se que o presente estudo foi realizado anteriormente à promulgação da Lei Federal no 11.947/2009 4 e da Resolução/CD/FNDE no 38 3, as quais estabelecem que, no mínimo, $30 \%$ do total de recursos repassados pelo FNDE devem ser destinados à compra de alimentos, preferencialmente orgânicos, produzidos pela agricultura familiar local, regional ou nacional, priorizando-se os assentamentos de reforma agrária, as comunidades indígenas e as quilombolas. Sendo assim, o percentual verificado entre as escolas Kaingáng pode ser considerado significativo, considerando-se que diversos autores apontam para a dificuldade no cumprimento da diretriz, em especial quando se trata de produtores indígenas. As dificuldades descritas incluem o fornecimento regular do volume necessário de gêneros e, ainda, o cumprimento de exigências burocráticas para a compra daprodução pelo PNAE 5,15.

No que se refere à presença indígena em cargos direta ou indiretamente ligados ao PNAE, os dados apontam para uma participação ainda limitada. Apesar de todos os vice-diretores das escolas Kaingáng serem indígenas, nenhuma escola contava, à época, com direção indígena. Por sua vez, a observação de que a maior parte das merendeiras era indígena e que a maioria tinha quatro anos ou mais de ensino formal constituiuse aspecto positivo. Contudo, a forma de contratação da grande maioria dessas profissionais era temporária e não cobria todo o período letivo (geralmente de abril a dezembro de cada ano), implicando alta rotatividade de merendeiras. Diante disso, para cobrir a ausência destas, realocavam-se profissionais de outras funções da escola, o que muitas vezes refletia na improvisação de cardápios (observado em um quinto das escolas). Soma-se a esse quadro o fato de nenhuma das merendeiras ter recebido da Secretaria Estadual de Educação do Rio Grande do Sul capacitação prévia sobre preparo das refeições e cardápios. A oferta regular dessas capacitações poderia impactar, dentre outros, em preparações de receitas que respeitassem o hábito alimentar local dos Kaingáng.

No que tange ao controle social do PNAE, observou-se que quase $70 \%$ dos entrevistados nas escolas Kaingáng desconheciam do que se tratava os CAE. Observação semelhante foi registrada em escola Xavánte 15 e em escolas da TI Raposa Serra do Sol 16. Outro aspecto relevante foi que menos da metade dos municípios que continham TI com as escolas Kaingáng contava com CAE. Em adição, a participação indígena na composição desse conselho foi observada somente em um de 19 municípios, traduzindo-se, consequentemente, em séria limitação ao controle social da alimentação escolar pelas comunidades indígenas. A baixa representação indígena nos CAE foi também fator comum em estudo conduzido em escolas Teréna 13. Segundo Gabriel et al. 6, a possibilidade de os CAE refletirem a visão da comunidade só se efetivará caso os membros se constituam por meio de mobilização e discussão social, reforçando-se uma fiscalização mais ativa dos conselhos no acompanhamento da elaboração dos cardápios, observando-se o respeito aos hábitos alimentares, a vocação agrícola regional e garantindo-se a utilização preferencial de produtos in natura. A etnografia de Gonçalves 15 indica, além disso, que, mesmo existindo representantes indígenas, não há necessariamente representação política como esperado pelas instituições estatais, a depender, entre outros aspectos, das formas nativas de organização política.

Quanto ao tipo de gestão do programa, a observação de que a maioria das escolas Kaingáng eram adeptas do formato escolarizado, difere do apontado em outros contextos indígenas $13,14,15,16$. Segundo Rodrigues et al. 27, o modelo de gestão escolarizado possibilita maior descentralização dos recursos e das ações, uma vez que são as escolas, juntamente aos CAE, que administram o Programa, o que garante maior autonomia às administrações escolares. Nessa direção, é interessante notar que a interrupção da alimentação escolar foi apontada somente por uma escola, cuja forma de gestão do programa era municipalizada. 
No contexto das escolas estudadas, era comum a presença de indígenas não matriculados, mas que participavam da partilha da alimentação escolar. A observação de comportamento semelhante para outras realidades indígenas 15,28 aponta que esse aspecto merece maiores investigações futuras. Gonçalves 15 descreve como, entre os Xavánte, a negação da partilha de alimentos constitui um comportamento socialmente inaceitável, o que se estende ao ambiente escolar, ao passo que o consumo da alimentação escolar por indivíduos não matriculados era essencialmente mal vista por gestores e executores do programa no nível local. Trata-se, sem dúvida, de um desafio adicional para o PNAE, a ser superado a partir da compreensão das especificidades de cada contexto. Vale assinalar a grande e já mencionada sociodiversidade indígena no país, que se traduz na necessidade de um olhar particular a cada caso. Talvez este ponto venha a suscitar a necessidade de maiores reflexões sobre o repasse de recursos do PNAE de acordo com os valores per capita para a alimentação escolar no contexto indígena.

Apesar de as CREs terem mencionado a existência de diferenciação dos cardápios sugeridos para as escolas indígenas e para as não indígenas, a dificuldade enfrentada pelas escolas indígenas para executá-los foi relatada por quase $90 \%$ destas. Infelizmente, neste estudo, não foi possível elucidar as dificuldades enfrentadas pelas escolas para a execução dos cardápios sugeridos pelas CREs. A inexistência de um Núcleo de Educação Indígena nas CREs observadas e a escassez de assessorias antropológicas a estas (regularmente ofertadas, à época, pela Secretaria Estadual de Educação do Rio Grande do Sul) pode explicar, em parte, a distância entre os cardápios sugeridos e aqueles passíveis de serem executados pelas escolas. A não diferenciação dos cardápios entre escolas indígenas e não indígenas foi também apontada por Gonçalves 15, em pesquisa realizada em uma escola indígena Xavánte, em Mato Grosso. Esse tipo de dificuldade, entretanto, não parece estar restrito às escolas indígenas. Estudo realizado em contexto não indígena, na Bahia, apontou que 59\% dos municípios não diferenciavam os cardápios ofertados entre escolas urbanas e rurais 7. Uma análise da utilização de preparações regionais em cardápios do programa destacou que $62 \%$ dos cardápios da Região Norte e 14\% daqueles da Região Sul não contemplavam sequer uma preparação regional semanal, a despeito da proposta de regionalização do programa ${ }^{11}$.

Quando analisados os cardápios propostos pelas CREs aos Kaingáng, observou-se que, para a maioria das escolas, as preparações que in- cluíam verduras, legumes, frutas, leguminosas e leite e derivados foram sugeridas para poucos dias (menos de $25 \%$ dos dias do mês) e que, com alguma frequência, embutidos (para 18,5\% das escolas) e enlatados (para $48,1 \%$ das escolas) eram sugeridos de $25 \%$ a $50 \%$ dos dias letivos no mês. Presença importante de itens alimentares industrializados foi também relatada nos estudos realizados entre os escolares Xavánte 15 e os Teréna 13. Este aspecto é preocupante e fere uma das diretrizes do $\mathrm{PNAE}^{3}$, que é de garantir o emprego de alimentação saudável e adequada nos espaços escolares. De fato, estudos diversos, realizados com etnias indígenas distintas, têm apontado elevadas prevalências de excesso de peso/obesidade na infância e adolescência indígena 20,29,30,31,32. Na literatura, aponta-se, como possíveis fatores explicativos desse aumento de peso entre os indígenas, a ocidentalização de dietas indígenas, caracterizadas por maior consumo de alimentos industrializados (com elevado teor de sódio, açúcar e gorduras) em detrimento do consumo de alimentos tradicionais 20,29,33,34,35. Pesquisas conduzidas no mesmo período e nas mesmas escolas a que se refere o presente estudo apontaram, além de prevalências expressivas de valores inferiores a -2 escores-z para o índice estatura/idade entre crianças $(15,5 \%)$ e adolescentes $(19,9 \%)$, percentual crescente do excesso de peso, desde a infância até a vida adulta 36 , mensurados por indicadores que avaliam a adequação do peso em relação à estatura. Outras investigações derivadas do contexto dessas escolas apontaram, também, importantes prevalências de acúmulo de gordura corporal entre crianças e adolescentes 37 , bem como alta prevalência de gordura abdominal entre os adolescentes (definida quando a relação cintura/estatura era superior a 0,5), especialmente entre aqueles do sexo feminino $(37,8 \%) 38$.

Foram estudadas $100 \%$ das escolas indígenas Kaingáng do Rio Grande do Sul, o que permite extrapolar as observações para este universo. Todavia, ressalvas devem ser feitas na extrapolação das observações para o universo das escolas indígenas do Estado do Rio Grande do Sul, uma vez que o estado possui também escolas indígenas que atendem aos Guarani, que não foram objeto de análise desta pesquisa. Uma limitação da análise dos cardápios apresentada no presente estudo relaciona-se ao fato de terem sido investigados somente os cardápios sugeridos pelas CREs às escolas, e não os cardápios efetivamente executados nestas. Ademais, pelo fato de, nos demonstrativos dos cardápios propostos não haver a discriminação das porções das preparações, neste estudo não foi possível realizar a quantificação da adequação calórica sugerida para os 
alunos indígenas Kaingáng em relação àquela proposta pelo PNAE 3 .

Outra dificuldade encontrada, quando da comparação dos resultados deste estudo com os pressupostos do PNAE, residiu, conforme anteriormente apontado por Gonçalves 15, no fato de o PNAE não dispor de elementos teóricos e documentos oficiais que referenciem sua operacionalização para as escolas indígenas. Segundo a autora, o que há de mais específico consta na Resolução/FNDE no 45 de 31 de outubro de 2003 24: "Na elaboração do cardápio, devem ser respeitados os hábitos alimentares de cada etnia, priorizando os alimentos semi-elaborados e in natura e respeitando sua vocação agrícola", considerando "a necessidade de se oferecer alimentação saudável e adequada, respeitando-se os hábitos alimentares e culturais particulares de cada etnia", com vistas a "garantir a implantação da Política de Segurança Alimentar e Nutricional e contribuir para a valorização e fortalecimento da cultura alimentar".

\section{Resumen}

Hay pocos estudios sobre el Programa Nacional de Alimentación Escolar (PNAE) en las escuelas indígenas del país. El objetivo es describir características de la gestión, la operatividad y los menús del PNAE de 35 escuelas Kaingáng de Río Grande do Sul, Brasil. Se trata de un estudio transversal, donde las informaciones del PNAE se obtuvieron por medio de cuestionarios aplicados a las Coordinaciones Regionales de Educación (CRE) y a las escuelas. Fueron obtenidos los menús sugeridos por las CRE a las escuelas. No existía el Centro para la Educación Indígena en las CRE. Todos los subdirectores eran indigenas, 26 (74,7\%) escuelas tenían gestión escolarizada y 34 escuelas hacían la compra de alimentos en mercados próximos. La mayoría de los cocineros $(62,9 \%)$ tenía un contrato de trabajo temporal y un 65,7\% eran indígenas. Se observó una baja oferta de verduras y leche y derivados en alrededor de $60 \%$ de los menús y de leguminosas y frutas en alrededor de un $80 \%$. Se indica la necesidad de más estudios sobre el PNAE indígena y se pretende subvencionar políticas públicas de salud, alimentación y nutrición para el espacio escolar indígena nacional.

Salud de Poblaciones Indígenas; Indios

Sudamericanos; Alimentación Escolar
Políticas públicas diversas como o PNAE, quando executadas em áreas indígenas, trazem impactos materiais e simbólicos para a cultura nativa, indicando a necessidade de estudos que produzam conhecimento sobre a realidade sociocultural e as circunstâncias históricas nas quais se insere a ação pública. Busca-se, assim, não só subsidiar esta última, mas também promover processos de negociação e discussão entre comunidades e poder público ${ }^{14}$. Por isso, aponta-se para a necessidade de novos estudos que gerem conhecimento sobre o PNAE indígena: funcionamento, fragilidades e potencialidades. A presente pesquisa pretende oferecer subsídios que poderão auxiliar os formuladores de políticas públicas de saúde, alimentação e nutrição no contexto das escolas indígenas no país.

\section{Colaboradores}

T. G. Castro participou da elaboração do estudo; da coleta de informações, análise e redação do manuscrito E. L. C. Matos participou da análise dos dados e redação do manuscrito. M. S. Leite, W. L. Conde e I. Schuch participaram da elaboração do estudo e redação do manuscrito. J.Veiga realizou a capacitação para a equipe de campo, participou da elaboração do estudo e redação do manuscrito. P. Zuchinali, L. A. Barufalde e C. L. C. Dutra participaram da coleta e registro de informações, análise dos dados e redação do manuscrito

\section{Agradecimentos}

À população Kaingáng do Rio Grande do Sul. 


\section{Referências}

1. Peixinho AML. A trajetória do Programa Nacional de Alimentação Escolar no período de 2003-2010: relato do gestor nacional. Ciênc Saúde Coletiva 2013; 18:909-16.

2. Ministério da Educação. Resolução/CD/FNDE no 32, de 10 de agosto de 2006. Estabelecer as normas para a execução do Programa Nacional de Alimentação Escolar - PNAE. Diário Oficial da União 2006; 11 ago.

3. Ministério da Educação. Fundo Nacional de Desenvolvimento da Educação. Resolução/CD/FN DE no 38, de 16 de julho de 2009. Diário Oficial da União 20089; 17 jul.

4. Brasil. Lei Federal no 11.947 de 16 de junho de 2009. Dispõe sobre o atendimento da alimentação escolar e do Programa Dinheiro Direto na Escola aos alunos da educação básica; altera as Leis nos 10.880, de 9 de junho de 2004, 11.273, de 6 de fevereiro de 2006, 11.507, de 20 de julho de 2007; revoga dispositivos da Medida Provisória no 2.178-36, de 24 de agosto de 2001, e a Lei no 8.913, de 12 de julho de 1994; e dá outras providências. Diário Oficial da União 2009; 17 jun.

5. Saraiva EB, Silva APF, Sousa AA, Cerqueira GF, Chagas CMS, Toral N. Panorama da compra de alimentos da agricultura familiar para o Programa Nacional de Alimentação Escolar. Ciênc Saúde Coletiva 2013; 18:927-35.

6. Gabriel CG, Machado MS, Schmitz BAS, Corso ACT, Caldeiras GV, Vasconcelos FAG. Conselhos Municipais de Alimentação Escolar em Santa Catarina: caracterização e perfil de atuação. Ciênc Saúde Coletiva 2013; 18:971-8.

7. Santos LMP, Araújo MPN, Martins MC, Veloso IS, Assunção MP, Santos SMC. Avaliação de políticas públicas de segurança alimentar e combate à fome no período 1995-2002. Programa Nacional de Alimentação Escolar. Cad Saúde Pública 2007; 23:2681-93.

8. Pipitone MAP, Ometto AMH, Silva MV, Sturion GL, Furtuoso MCO, Oetterer M. Atuação dos conselhos municipais de alimentação escolar na gestão do Programa Nacional de Alimentação Escolar. Rev Nutr 2003; 16:143-54.

9. Mello AL, Vidal JPO, Sampaio LR, Santos LAS, Freitas MCS, Fontes GAV. Perfil do nutricionista do programa nacional de alimentação escolar na região Nordeste do Brasil. Rev Nutr 2012; 25:119-32.

10. Belik W, Chaim NA. O programa nacional de alimentação escolar e a gestão municipal: eficiência administrativa, controle social e desenvolvimento local. Rev Nutr 2009; 22:595-607.

11. Chaves LG, Mendes PNR, Brito RR, Botelho RBA. O Programa Nacional de Alimentação Escolar como promotor de hábitos alimentares regionais. Rev Nutr 2009; 22:857-66.

12. Muniz VM, Carvalho AT. O Programa Nacional de Alimentação Escolar em município do estado da Paraíba: um estudo sob o olhar dos beneficiários do Programa. Rev Nutr 2007; 20:285-96.

13. Pessôa MCMB. Programa Nacional de Alimentação Escolar em escolas da Terra Indígena Buriti - Mato Grosso do Sul [Dissertação de Mestrado]. Campo Grande: Universidade Federal de Mato Grosso do Sul; 2013.
14. Giordani RCF, Gil LP, Auzani SCS. Políticas públicas em contextos escolares indígenas: repensando a alimentação escolar. Espaço Ameríndio 2010; 4:25-51.

15. Gonçalves RC. A diversidade sociocultural no Programa Nacional de Alimentação Escolar: uma etnografia da alimentação escolar indígena entre os Xavánte de Parabubure, Mato Grosso [Dissertação de Mestrado]. Florianópolis: Universidade Federal de Santa Catarina; 2012.

16. Oliveira ZA. Segurança alimentar nas escolas indígenas do Centro Willimon da Terra Indígena Raposa Serra do Sol - RR [Dissertação de Mestrado]. Brasília: Universidade de Brasília; 2013.

17. Departamento de Atenção Básica, Secretaria de Atenção à Saúde, Ministério da Saúde. Política Nacional de Alimentação e Nutrição. 2a Ed. Brasília: Ministério da Saúde; 2003. (Série B. Textos Básicos de Saúde).

18. Instituto Brasileiro de Geografia e Estatística. Censo demográfico 2010: características gerais dos indígenas. Rio de Janeiro: Instituto Brasileiro de Geografia e Estatística; 2012.

19. Santos RV, Coimbra Jr. CEA. Cenários e tendências da saúde e da epidemiologia dos povos indígenas do Brasil. In: Coimbra Jr. CEA, Santos RV, Escobar AL, organizadores. Epidemiologia e saúde dos povos indígenas no Brasil. Rio de Janeiro: Editora Fiocruz; 2003. p. 13-47.

20. Leite MS. Sociodiversidade, alimentação e nutrição indígena. In: Barros DC, Silva DO, Gugelmin AS, organizadores. Vigilância alimentar e nutricional para a saúde indígena. Rio de Janeiro: Editora Fiocruz; 2007. p. 181-210.

21. Garnelo G, Pontes AL. Saúde indígena: uma introdução ao tema. Brasília: Secretaria de Educação Continuada, Alfabetização, Diversidade e Inclusão, Ministério da Educação; 2012. (Coleção Educação para Todos).

22. Schuch I. Perfil socioeconômico e alimentar das famílias indígenas Kaingang de Guarita, RS [Dissertação de Mestrado]. Campinas: Universidade Estadual de Campinas; 2001.

23. Almeida PH. Comida forte e comida fraca: alimentação e fabricação dos corpos entre os Kaingáng da Terra Indígena Xapecó [Dissertação de Mestrado]. Florianópolis: Universidade Federal de Santa Catarina; 2009.

24. Secretaria de Atenção à Saúde, Ministério da Saúde. Guia alimentar para a população brasileira: promovendo a alimentação saudável. Brasília, 2006.

25. Fundação Nacional do Índio. Instrução normativa no 01/PRESI de 29 de novembro de 1995. Brasília: Fundação Nacional do Índio; 1995.

26. Rodrigues PS. O programa nacional de alimentação escolar: história e modalidades de gestão. Revista Brasileira de Política e Administração da Educação 2013; 29:137-55.

27. Alvares MMA. Educação indígena na escola e a domesticação indígena da escola. Boletim do Museu Paraense Emílio Goeldi 1999; 15:54-83. 
28. Leite MS, Santos RV, Gugelmim SA, Coimbra Jr. CEA. Crescimento físico e perfil nutricional da população indígena Xavánte de Sangradouro-Volta Grande, Mato Grosso, Brasil. Cad Saúde Pública 2006; 22:265-76.

29. Kühl AM, Corso ACT, Leite MS, Bastos JL. Perfil nutricional e fatores associados à ocorrência de desnutrição entre crianças indígenas Kaingáng da Terra Indígena de Mangueirinha, Paraná, Brasil. Cad Saúde Pública 2009; 25:409-20.

30. Mondini L, Rodrigues DA, Gimeno SGA, Baruzzi RG. Estado nutricional e níveis de hemoglobina em crianças Aruak e Karib - povos indígenas do Alto Xingu, Brasil Central, 2001-2002. Rev Bras Epidemiol 2009; 12:469-77.

31. Coimbra Jr. CEA, Santos RV, Welch JR, Cardoso AM, de Souza MC, Garnelo L, et al. The First National Survey of indigenous people's health and nutrition in Brazil: rationale, methodology, and overview of results. BMC Public Health 2013; 13:52.

32. Gugelmin AS, Santos RV. Ecologia humana e antropometria nutricional de adultos Xavante, Mato Grosso, Brasil. Cad Saúde Pública 2001; 17:313-22.

33. Gimeno SGA, Rodrigues D, Pagliaro H, Cano EN, Lima EES, Baruzzi RG. Perfil metabólico e antropométrico de índios Aruák: Mehináku, Waurá e Yawalapití, Alto Xingu, Brasil Central, 2000/2002. Cad Saúde Pública 2007; 23:1946-54.
34. Lourenço AEP, Santos RV, Orellana JDY, Coimbra Jr. CEA. Nutrition transition in Amazonia: obesity and socioeconomic change in the Suruí Indians from Brazil. Am J Hum Biol 2008; 20:564-71.

35. Castro TG, Schuch I, Conde WL, Veiga J, Leite MS, Dutra CLC, et al. Estado nutricional dos indígenas Kaingáng matriculados em escolas indígenas do Estado do Rio Grande do Sul, Brasil. Cad Saúde Pública 2010; 26:1766-76.

36. Barufaldi LA, Conde WL, Schuch I, Duncan BB, Castro TG. Bioelectrical impedance values among indigenous children and adolescents in Rio Grande do Sul, Brazil. Rev Panam Salud Pública 2011; 30:39-45.

37. Castro TG, Barufaldi LA, Schlussel MM, Conde WL, Leite MS, Schuch I. Waist circumference and waist circumference to height ratios of Kaingáng indigenous adolescents from the State of Rio Grande do Sul, Brazil. Cad Saúde Pública 2012; 28:2053-62.

38. Ministério da Educação. Fundo Nacional de Desenvolvimento da Educação. Resolução CD/ FNDE no 45, de 31 de outubro de 2003. Diário Ofical da União 2003; 4 nov.

Recebido em 20/Dez/2013

Versão final reapresentada em 06/Abr/2014

Aprovado em 05/Mai/2014 